\title{
PROBLEMS IN COMMUNICATION BETWEEN BUSINESSES AND TECHNICAL EDUCATION SYSTEM
}

\author{
Maciej Szafrański, Klaudyna Bogurska-Matys, Marek Goliński \\ Poznan University of Technology, Faculty of Engineering Management, Poland \\ Corresponding author: \\ Maciej Szafrański \\ Poznan University of Technology \\ Faculty of Engineering Management \\ Chair of Marketing and Economic Engineering \\ Strzelecka 11, 60-965 Poznań, Poland \\ phone: $(+48) 612244520$ \\ e-mail: maciej.szafranski@put.poznan.pl
}

Received: 2 February 2017

ABstract

Accepted: 31 March 2017

This paper presents how some communication problems between business and Technical Education System (TES) can be reduced. This comes to a misunderstanding of the needs of entrepreneurs for the knowledge and skills, in this paper treated as a resource on the market. The authors explain why debated issue falls in the area of corporate management. It identifies one of the reasons hindering the solution of problems. In order to clarify the issues it references the achievements of analytic philosophy of language and the theory of communication code. It proposed a method of facilitating the solution of the problem, which is being implemented since 2016 by the research team, co-created by the authors of this publication. The aim of the development of this publication is to supplement the theoretical and practical knowledge of management in manufacturing companies and others with high technical potential, where there is a large, growing and rapidly changing demand for knowledge and technical skills.

KEYWORDS

management of knowledge, knowledge networks, enterprise networks, communication model.

\section{Introduction}

The company as an open system remains in the relationship with the environment, which results in their interactions [1]. Changes in the enterprise and its environment cause volatility interactions and relationships. The company must adapt to changes in the environment and at the same time, to the extent, possibly influence the environment [2]. There are a number of environmental factors relevant to the efficient and effective functioning of the company, and resources are one of these. One of the categories of resources is the knowledge and skills [3], which may arise in the company or be sourced from outside. Knowledge and skills are assigned to people. These are the qualities [4], which can be identified as an individual or joint. For the knowledge and human skills to be beneficial for the company they must be able and willing to use them in the activities lead- ing to the achievement of the objectives defined by the company. The concept of "willing" here is related to motivation [5], which is one of the functions of management. The term "able" is in turn associated with another function of management - organization [6]. For these functions to occur, it is first necessary to plan the use of resources which are knowledge and skills (another management function) [7]. If the company knows, what knowledge and skills are needed, they must be ensured, in particular gined. Acquisition of these assets is similar to obtaining any other resources to guarantee the smooth operation of the enterprise [8].

As with any other resources, knowledge and skills can be found on the market, offered by their suppliers. Providers of the knowledge and skills can be, for example, individuals (prospective employees, authors of books), other operators in the market (for example service companies) or institutions shaping the knowl- 
edge and skills of future labor market participants (eg. schools, colleges, training companies). To communicate with the suppliers of knowledge and skills it is necessary to define needs for such resources. Specification has to be developed, for it to be exchanged on the market. It would be difficult to sell or buy any goods that are not properly defined. To be able to describe some resources such as the knowledge and skills it is necessary to use appropriate language that is understood by the parties involved in the exchange. The use of this language is performed in the communication process. Such a process exhibits a convergence model of communication language proposed by R.O. Jacobson [9].

The model is presented in Fig. 1. An important component is the code of communication, which consists of: dictionary, grammar and composition (rules) [9]. The result of the application of the code is the creation of the names of various types of knowledge and skills, which usually take the form of phrases or simple sentences. Communicating parties give them meaning.

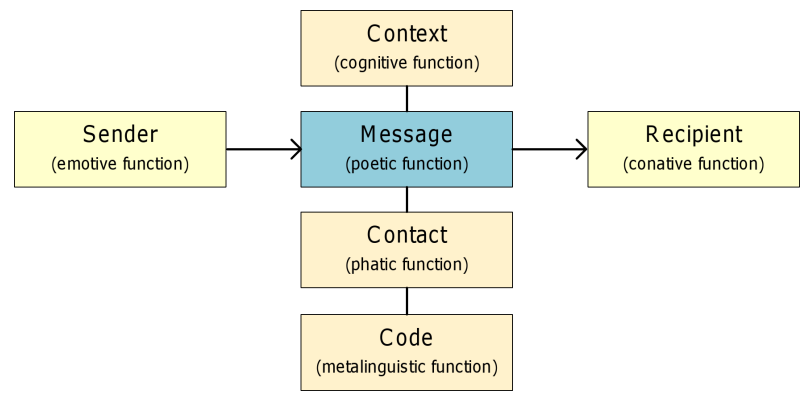

Fig. 1. Model of Language Communication. Source: R.O. Jacobson [9].

Understanding of the communication code by the communicating parties is necessary in order to effectively be able to exchange resources. To understand the meanings of names, in addition to knowledge of the code, it is necessary to get to know each other and to know the context in which those names are used. The case of the exchange of knowledge or skills includes for example: the objectives set out in the company, the method used to develop the code, motivation of the job-seeker and other factors.

The result of the communication should be to understand what the parties need and what the company can and can not offer the other side. It was already mentioned that the other side can not only be a single candidate for the job but the entire training institution of future candidates or their entire system. In the business environment such various systems can be distinguished.
For a group of manufacturing companies technical competence is particularly important [10-12], taking into account their needs, it is reasonable to distinguish Technical Education System (TES), which is a subsystem of Vocational Training System (VES). The specific character of the functioning educational system can arise difficult to close gap on the market of competences resulting from noncompliance of these systems to meet the needs of enterprises. The following paragraphs will first outline the specifics of the system of Technical Education in Poland. Then explained in more detail will be one of the causes of the problem of communication between enterprises and the system of Technical Education and, finally, will be presented a proposal to improve this process by eliminating the identified causes.

\section{The System of Technical Education vs. the Labor Market}

Through the Technical Education System (TES) it is understood, in this paper, the subsystem of Vocational Training aimed at developing the knowledge and technical skills. The model of Vocational Training in Poland, with ideologically highlighted in the system of Technical Education, is presented in Fig. 2. The Vocational Education System (VES) evolves, and in the case where the impact upon them have, for example, political factors, is changing by leaps and bounds. An example of such abrupt changes are shown in relation to the group of mechanical jobs in Fig. 3. The system shown in Fig. 2 should be regarded as an example applicable in a given time. With TES it determines that it is the subject to the same rules as the functioning of VES. Its distinction is possible because of the special characteristics which differentiate it from the host system. Features leading to the award TES can be:

- different knowledge and technical skills compared to other category of knowledge and skills of trained VES,

- a separate group of needs for knowledge and technical skills, as reported by the companies,

- different methods of learning of competence or technical skills,

- specific equipment and technology, the use of which is essential in the process of education in terms of knowledge and technical skills,

- different pace of development techniques and technologies used in education knowledge and technical skills in relation to the same pace in the process of training other than technical,

- other requirements regarding health and safety, and fire protection. 

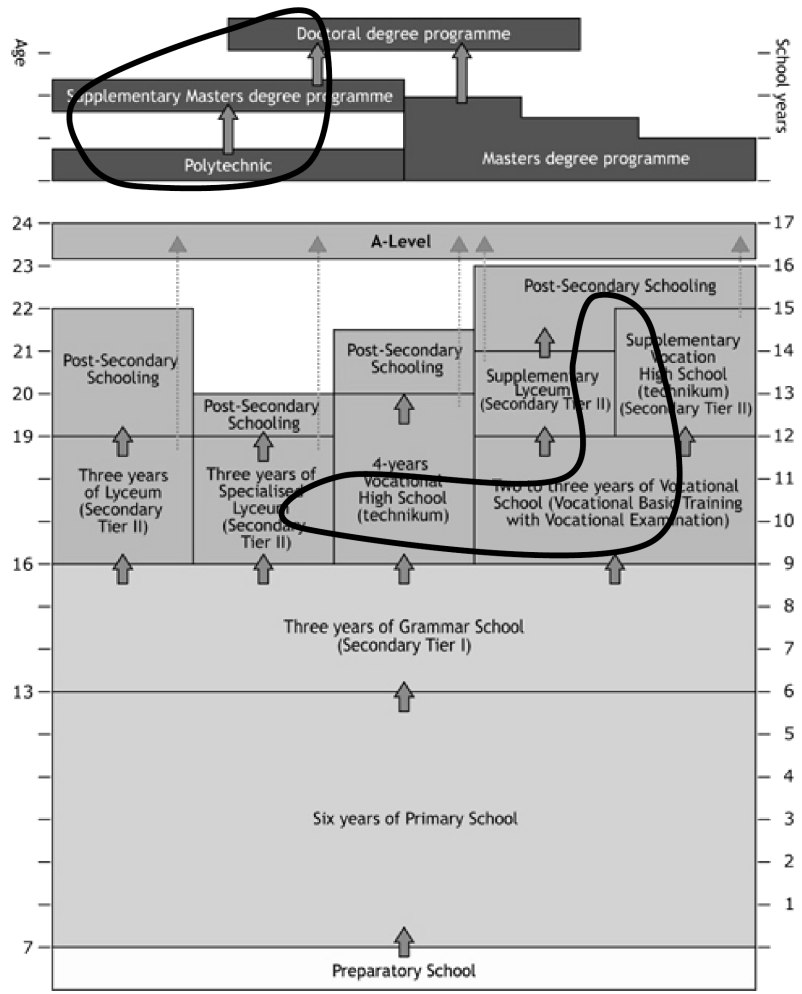

Fig. 2. Model of the Polish Education System. TES curves distinguished within the VES. Source: R. Piwowarski [13].

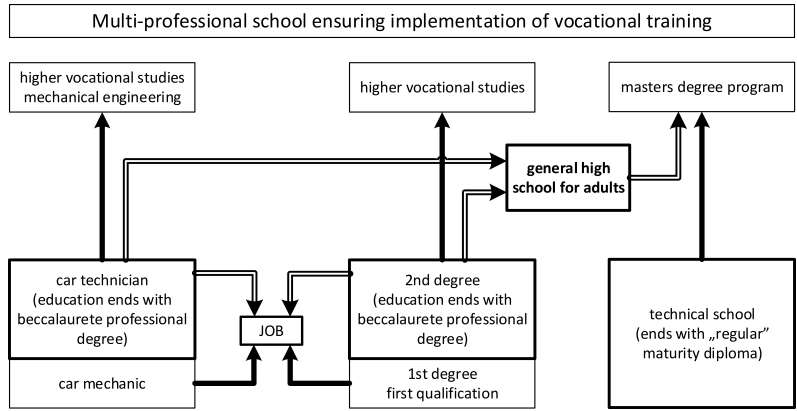

Fig. 3. Model of Polish Education - 2017 Vocational Education System changes [14].

Of course, there are more factors. The concepts of knowledge and technical skills stands out starting from the definition of technology [12].

The literature widely describes mismatches in the VES and in the TES to the needs of the labor market $[15-18]$. One of the problems identified are differences in the use of language when describing knowledge and skills in companies and in the Education System. Their diversity stems among other things, from different linguistic codes that relate to knowledge and skills. The parties did not communicate using a common code but their own, different, which causes problems in communication. From a business perspective, these problems may result in:
- increased risk of improper employment of an employee,

- prolonging adaptation of the employee in the workplace, for which he was hired,

- increased costs associated with the recruitment and training of employees, and thus the costs of prevention of cost increase [19],

- increases the risk of inconsistencies in processes and products.

The causes of differences in the codes of communication in companies and in the TES, on the knowledge and technical skills are numerous and they change over time. For example, in the system of Upper Secondary Technical Education in Europe (medium level), some of them are:

- the perceived lack of common purpose of Vocational Schools operating on the basis of national legislation, with the objectives formulated in businesses [20, 21],

- frequent insufficient teachers knowledge of the industries professions [22],

- lack of adequate facilities in the schools [23],

- mismatched competence of graduates [24],

- lack of a link between the Systems of Education at its various levels, despite the attempts of their integration [24] At the same time communication using a common code is hampered by factors flowing from the principles of the functioning of businesses. Some of them are described in the papers published by M. Szafranski [25, 26].

The above-mentioned factors can be considered in the category of disruptions of the communication process. They lead to difficulties in the application of the same language of communication, including the code of the language, which, in relation to knowledge and skills can be called the code of knowledge and skills. Preventing the occurrence or build-up of misleading factors becomes easier after taking into account the nature of language.

\section{The language code as one}

\section{of the causes of the problems}

\section{in communication between companies} and the System of Technical Education

Language has for centuries been the subject of interest in philosophy. Knowledge of its nature comes from analytical philosophy of language. In the context of its achievements can be concluded that the problems of communication between businesses and TES are mostly operational problems in a much wider conducted discourse about language, meaning, language, and concepts. The analytic philosophy of 
language dispute begins with whether it is possible to communicate by means of an ideal language, or method of learning about reality must be developed its fragments with reference to the colloquial language. Precursors of this trend were philosophical G. E. Moore and B. Russell [27, 28]. The development of views on the dispute between supporters of the ideal language and everyday language are illustrated in Fig. 4. For the development of publications were used [29-36]. If we assume that the knowledge and technical skills are one of the categories of objects of knowledge, and refer to them relating to the language and its function in the process of cognition, we can draw the following conclusions:

- there are many philosophical trends, which can be a starting point for research on the dictionary of skills,

- from an aesthetic point of view, the philosophy of ideal language could be a role model to shape a code of knowledge and skills,

- due to the fact that the requirements for knowledge and skills are formulated in businesses, they are expressed in everyday language,

- achieving the philosophy of ordinary language can be a stimulus to accelerate work on the improvement of this code, in order to improve the communication process between entrepreneurs and TES,
- because of the connection of this philosophy with qualitology, having its origins in the management of enterprises, the simultaneous use of the accomplishments of these sub-disciplines of knowledge can also have a positive impact on communication in the requirements for competence,

- the diversity of views on language shows that language as an object of knowledge is very complex, hence the problem of creating a common code of communication that would be understood by the communicating parties, is also difficult,

- minimizing this problem depends largely on the degree of mutual understanding between the parties involved in the communication process,

- parties should together be in a relationships and communicate, which will condition the maintenance and improvement of communication processes,

- language is an element of reality dependent not only on the body but also on the relationship between the parties, hence its shape affects not only the perception of the participants, but also the complexity of the relationship between them,

- it is necessary to improve methods and tools of sharing codes of knowledge and skills of businesses and TES.

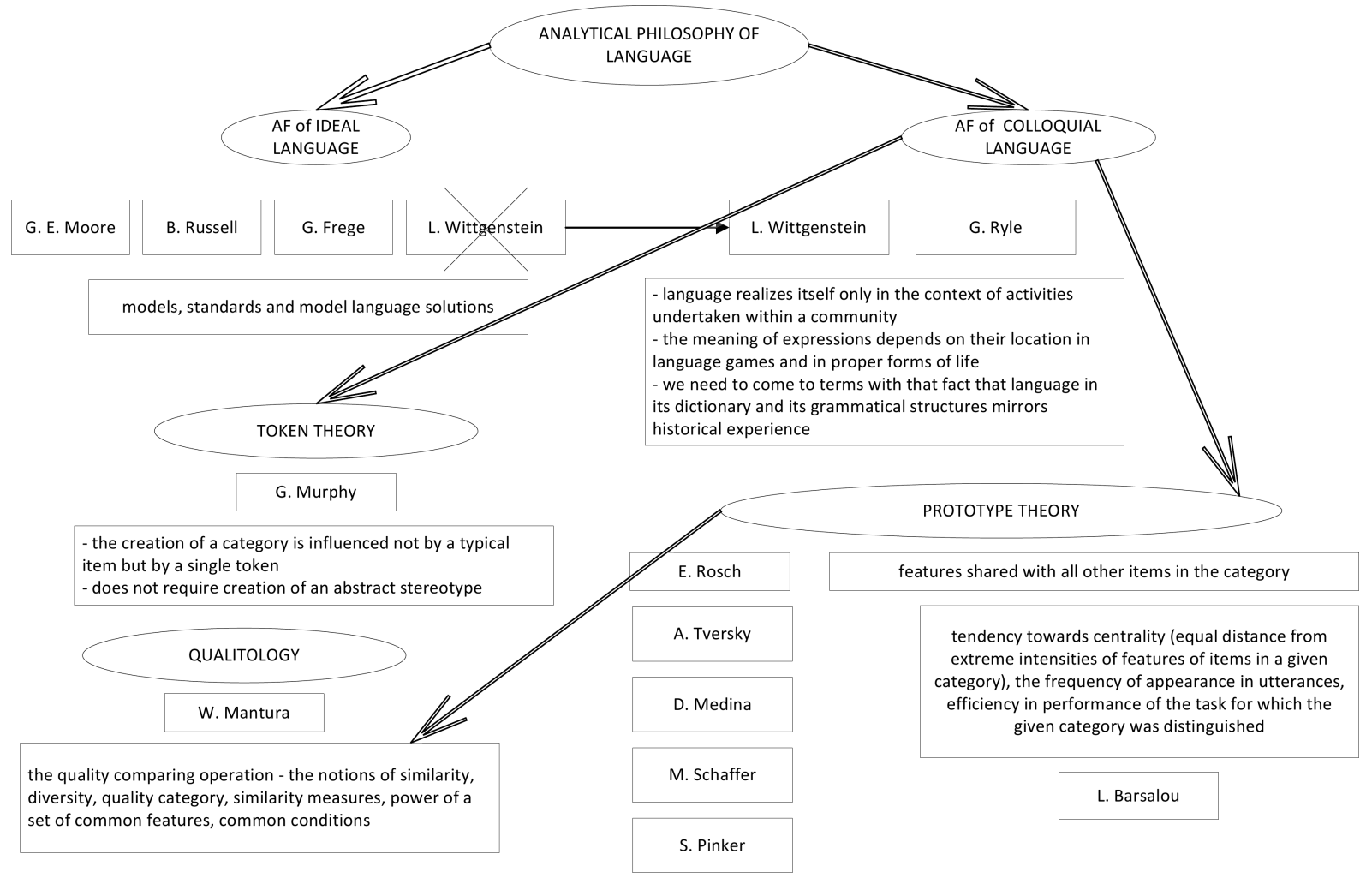

Fig. 4. Development of ideas analytical philosophy of language. Source: own work. 


\section{The proposal to solve the problem of communication between business and Technical Education System}

Constantly there are new attempts to develop common for entrepreneurs and TES code of knowledge and skills. First, one can cite legal solutions. Their advantage is the standardization of the code, but the inertia in implementing changes in this code means that it is still not adjusted to the rapidly following changes in technology and technique, and thus the demand for business knowledge and technical skills. Examples of such codes in Poland can be a Core Curriculum of Vocational Education (CCVE) [37] or training programs in Higher Technical Education and, in particular collections of learning outcomes. Additionally, for example CCVE way of creating code in the dictionary, means that they have a high science value, but limited practical value. The difficulty in understanding the code are repeatedly pointed by CCV employers in the framework of research projects carried out among others, by the authors of this paper. Worthy mentioning are for example: Wielkopolska Region Monitoring and Forecasting (2010-2012) [38] The Proffessionals Time - Wielkopolska Region Vocational Training (20132015) [12, pp 246]. Another example of codes are used on the job search portals such as pracuj.pl, totaljobs.com, indeed.co.uk, caterer.com, catererglobal.com, by commercial enterprises forming them in order to earn a matching employers and job seekers. These codes are not used in the TES. These codes are standardized codes, imposed on employers, showing characteristics of ideal codes. One would accept them assuming the constancy of the enterprise environment and the willingness of enterprises and TES for the adoption and use of one of these codes, which would be preceded by training in order to familiarize with the vocabulary and the meaning of words used in the codes.

The proposal to develop a new code of knowledge and skills was born at Poznan University of Technology in 2015. The solution is planned to rise to the code based on everyday language. Imperative entities imperative in its creation would be entrepreneurs, because their needs on the labor market should be satisfied. TES should serve the economy and should satisfy, to the extent possible its expectations. There will always be a number of barriers that make it difficult to meet the expectations of entrepreneurs (budget, time, etc.). At least one of them can be reduced - misunderstanding between the parties arising from the use of other communication codes. For this purpose, the project team, whose members are the authors and director M. Szafrański, acting within the project Time for Professionals BIS - Professional Wielkopolska (TfP BIS - planned implementation from November 2015 to December 2022), funded by the Wielkopolska Regional Operational Program, has developed method of maintaining common for entrepreneurs and TES code knowledge and skills.

\section{The general process of developing the code}

The present approach assumes continuity of operations, as previously signaled variability of conditions in which businesses operate, makes the language, and the same code of communication used in them variable and subject to constant change. In this context, it is not possible to develop an unchanging code, and its abrupt changes are usually too late, hence impractical. Grabbing is not excluded if the rate of change of dictionaries will not be slower than the rate of change in the requirements for knowledge and skills in the workplace of companies. Continuity of the activities in the field of creation, and therefore both a maintenance of the code of knowledge and skills is also due to changes in the size and structure of companies in the market and with the limitations of budget and time, which can not be reached with a proposal of cooperation to all companies at once [39]. Incidentally, some companies do not want (eg. a lack of knowledge about the importance of properly defining the needs for knowledge and skills) or may not want (eg. political reasons or on secrecy) to participate in the creation of a code of knowledge and skills. In the first phase of activities (Fig. 6) it is necessary to adopt a minimum sample of companies and categories of positions necessary to initiate the process of creating the code. It is best if they will be determined taking into account the needs of not only business but also social needs. So did the team working on the project TfP BIS, in addition to the composition of the authors of this paper include M. Graczyk-Kucharska, M. Spychała, E. Juchniewicz. Limitations of time and resources forced to limit the scope of work. They focus on positions related to 8 technical professions, training future employees in Wielkopolska Region. Introduced were the following criteria limiting the scope of work, the adoption of which does not affect the versatility of this method:

- geographical area - Wielkopolska Region - activities are financed by the Government of Wielkopolska Region, the authorities recognize the importance of improving communication between businesses and TES.

- 8 technical professions: IT, ICT, electrical, electronics, mechatronics, mechanics, logistics, freight forwarder - medium level technical was chosen be- 
cause this type of specialists is very high demand in the region's companies (cf. [12, pp. 235]), the selected jobs are linked to other actions undertaken to adapt the TES to the needs of the labor market. Among other things, the project TfP BIS Poznan University of Technology are prepared laboratories for extra-curricular activities for students in these professions, to develop a network of cooperation between entrepreneurs, Technical School and TES and accelerate the diffusion of knowledge; some laboratories already in place from 2013 [40], others are created,

- the size of companies - to contribute to the code competence of the invited companies are large or medium due to the following reasons: they have a significant impact on the labor market, including suppliers, whose knowledge and skills are partly dependent on the orders of large companies, there is in them reproducibility jobs, the description of which should lead to the creation of reference models discussed below,

- the number of cooperating companies - the greater the number of companies contributing to the creation of a code of knowledge and skills, preferably including; their collection can steadily grow, however, to start work and make the first character code, it is assumed that involved in the collaboration will be a minimum of 25 companies.

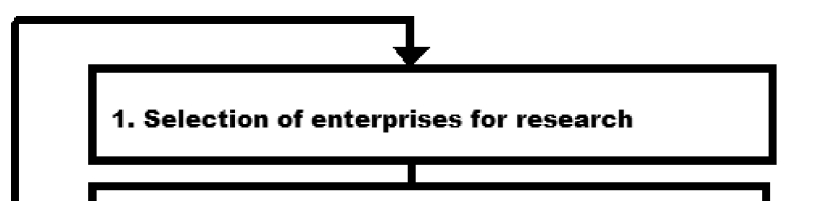

2. Establishing communication with companies

3. Analysis of the job descriptions used in the companies

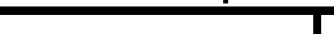

4. Developing competence profiles based on job description cards

5. Development of reference models based on jobs

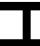

6. Development of codes of knowledge and skills

Fig. 5. The overall process of developing a code of knowledge and skills based on everyday language used in businesses. Source: own work.

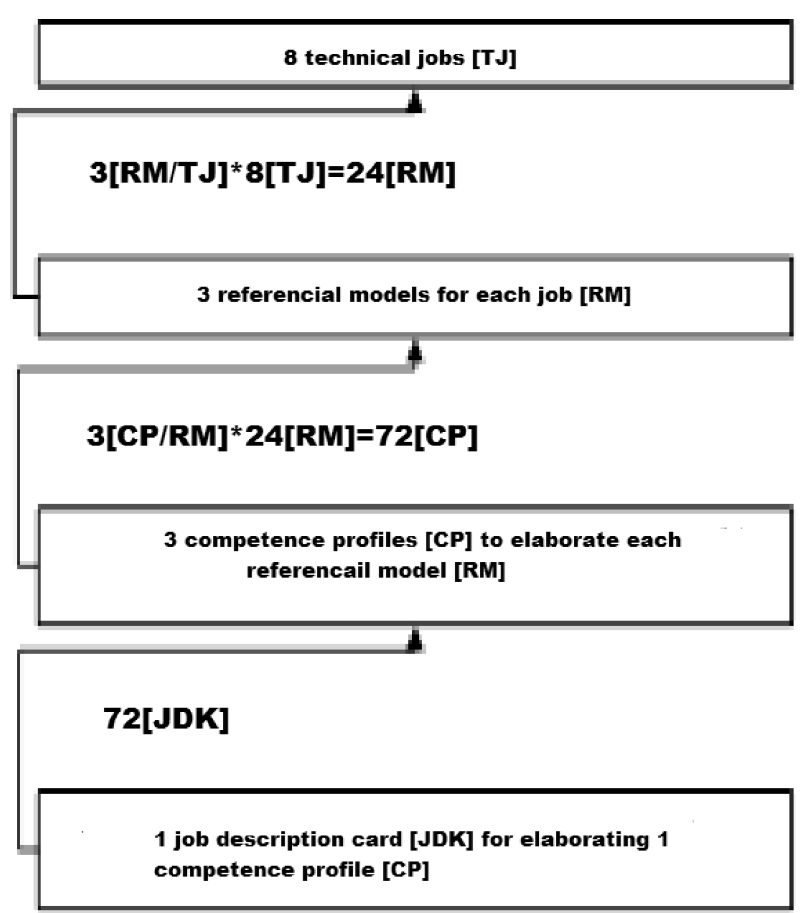

Fig. 6. Relationship between competition, reference models, profiles and job description cards in the project "Time for Professionals BIS - Professional Wielkopolska". Source: own work.

The second stage consists in establishing cooperation with businesses. For example, the project TfP BIS in the period from May to December 2016 contacted 75 companies, of which 73 expressed their readiness to talk. Contact should be preceded by actions such as:

- design methods to develop a code of communication (test method), whose elements in the project TfP BIS are presented below in the context of the further stages of work,

- ratio test method description language into entrepreneurs,

- development of a checklist of topics for meetings in enterprises,

- reparation of information materials,

- development of a schedule of meetings,

- ensuring the budget to maintain relationships after the initiation of cooperation.

Analysis of the job description cards used in companies, constitutes the third phase of work in the process of developing a code of knowledge and skills is based on reading of the cards that the company will agreed to give. Types of positions should take into account the criteria established in the first stage. In the course of analysis correctness, repetition, convergence and divergence occurring between the content of job descriptions should be observed initially in 
different companies. The cards are a carrier of information about the functions that employees perform on theirs positions. Their analysis allows conclusions to be drawn, what knowledge, skills and qualifications (divided into professional, social, and socioprofessional) are required in the workplace. The TfP BIS project planned, that in relation to the selected 8 technical professions 72 job description cards will be analyzed, which was carefully considering the further course of the project.

In the fourth stage, based on information from the job description cards, proposed is development of competence profiles, or descriptions of what knowledge and skills are required from an employee on a given workstation. After developing the initial profiles they should be consulted with the companies for two reasons. Firstly, there must be certainty that formulated profile name of competence of individual categories of knowledge and skills reflect the intentions of entrepreneurs included (not always openly and explicitly) in the names of the tasks. Secondly, consultation is required to determine not only if, but at what level should the knowledge and skills be developed. The rating level requires scaling. The TfP BIS project adopted 6 grades scale. Developing competency profiles consists, based on a given company, of one or two visits to each of them. The number of profiles should be consistent with the number of job description cards analyzed, unless it turns out that some of these cards are not suitable to be taken into account, then there will be more card analyzes in the study than the resulting competency profiles. Discarded may be the cases where the cards do not correspond specifically with the testing profession or are too general. The resulting set of competency profiles allows to develop, based on the set, the reference model of knowledge and skills in the workplace, which the research team called The Workstation Reference Models. The concept of the reference model is used herein in accordance with the general definition [40]. Figure 6 presents the scheme of activities leading to the development of this code in the TfP BIS project. The names of the expected categories of knowledge and skills in the workplace gathered under reference models contain the code of language of the entrepreneurs.

Execution of tasks presented in Fig. 5 is scheduled for the end of August 2017.

The next stage may be development of dynamic codes of knowledge and skills in professions. The TfP BIS project does not exclude such action. Questioning of the validity of the implementation of the sixth stage of the project is the fact that the rate of change in technology causes constant changes in the characteristics of the occupations. For example, the fast pace of development of technology and science questions whether one should use the name "computer technician", what happens in Polish VES, or whether to treat the classification of occupations as a dynamic, focusing on improving jobs description codes. In the case of job descriptions and names a significant problem is noticeable with the diversity of names being used in enterprises, which is a disadvantage of the use of colloquial language. Limiting this defect requires institutions to cooperate on the development of a code of knowledge and skills and to remain together in relationships and stimulate these relationships. It concerns both the company and the institutions or TES, wider VES. That is why, among other things, in Wielkopolska Region there are attempts to develop Wielkopolska Region Network for Education and Economy [41-43], the scope of which in the future may be extended. The development of this network is being supported by an IT tool www.system.zawodowcy.org, functioning since 2012 [44]. Changes in the code of competence undertaken in the framework of the TfP BIS project are also action for the improvement of this system.

\section{The Visual Code - Communication Component Code}

Professional Communication requires a consistent use of current, coherent, precise and unambiguous terminology [45]. Such a desirable state of affairs is not natural, which can be explained by the concept of Semiotic Triangle by C.K. Odgen and I. Richards [46] - see Fig. 7. It follows the tripartite relationship between the real object, concept and term [46]. The ideal situation is one in which a single term can only be attributed by one concept, which in turn corresponds to exactly one real object, and therefore there is no possibility of ambiguity [47].

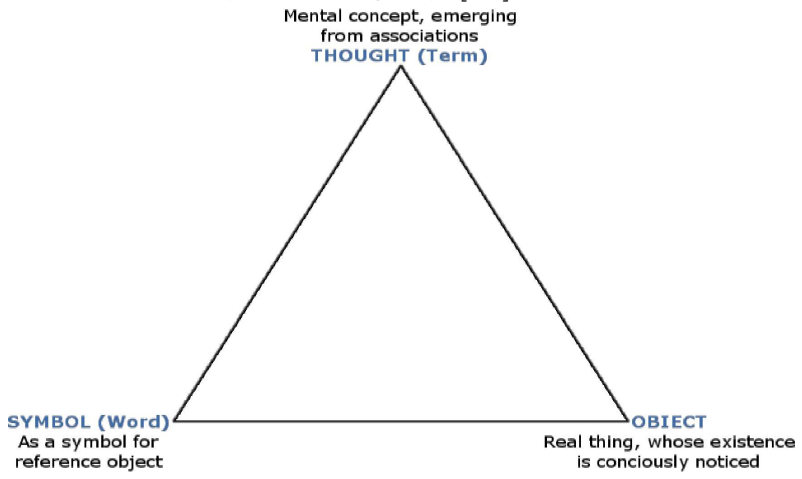

Fig. 7. Semiotic Triangle - the tripartite relationship between the real object, concept and term [46]. 
Modern technology, ubiquitous in everyday life, has introduced various forms of communication with the technology and about the technology. There are many different kinds of manuals, installation guides, service books, product descriptions, as well as job description reference models described here earlier. Social communication and technical assistance between the entrepreneur and the recipient of the message (customer, supplier, employee) is carried out through these documents. The above-mentioned sources of information are often a conglomeration of two languages: visual (sign) and verbal. In addition to the language signs they contain in their structure the nonlinguistic signs, and in particular images [46].

Like sign language, the picture may be of a simple or multi-dimensional significance. There are three levels of perception of meaning (connotative areas) listed by the semantics. The first level is a direct and primary recognition of the importance of the image, or a simple identification of the object based on the generally known properties. The second level is the semantic connotation as assigning attributes constituting the cultural knowledge of the referent. A third, much narrower connotation level, is the perception of the individual characteristics forced by certain environment, the level of erudition, taste and tradition [48]. According to Mr Lakoffe'a and M. Johnsone'a one can risk transfering theory called radial structure of meaning [49] in the area of linguistics into images, as the nature of perception of meaning [50] is common for different ways of communication. This theory states that there is a tendency to transmit a given object most typical of the possible meanings. Seen image is interpreted by its meaning without a thorough analysis.

Knowledge of the mechanisms of transmission of meanings of seen images is the key to the design of contemporary visual messages [47]. The deliberate articulation of the specific characteristics and meanings is the essence of creating new characters and brands, and this determines the degree of recognition of the importance and strength of associations, and thus the effectiveness of the final planned message. A sign, according to the classical definition, is any intentionally prepared message as a system of things or phenomena, which has the intention of recipient understanding the message and invokeing associations and specific thoughts. Signs are everywhere - according to Peirce's semiotic theory of signs. Peirce is considered to be the creator of modern semiotics, his works, and included in them concepts and terms, are a prerequisite of modern research and reflection carried out in this field [51], the world is a universe of characters. Peirce distinguishes three types of signs: indexes, icons and symbols. Important to induce the recipient planned response is to give the impression form appropriate to the content. Form of the sign must be simple, and each element, which is not necessary, weakens its impact.

Currently, established over the centuries position of writing in Western culture, loses its importance. At some point in time the handwritten message triumphed over spoken transmission, and today audiovisual media take place of that handwritten message [52]. This is how Stanisław Dylak describes the understanding of visual language: "Today the ubiquitous flood of iconic representations, light manipulation, movement and colors representing many shades of reality, it is necessary to clarify, to objectify and to master this language" [53].

Graphic symbols, created in accordance with the radial structure of meaning, which can be used in reference models developed within the "Time for Professionals BIS - Professional Wielkopolska" project, can become a visual language code, showing competence, skills and qualifications.

\section{Summary}

The acceleration of technological progress means that in companies with a large demand for technical knowledge and skills shortage of this resource is present. The solution could be accelerated learning and continuous improvement of its quality. Unfortunately, the Technical Education System (TES), which is a subsystem of Vocational Education System (VES), adapts to the changing needs of businesses is too slow. One of the issues described in this paper, is the discrepancy of the used codes of communication that make it difficult for business entities and TES to communicate. This problem has its origins in the nature of language, which responds to changes taking place in communicating entities and dynamic relationship between them. Although the problem falls, as noted in this paper, in the area of corporate governance, it's easier to understand its nature by reaching to the achievements of analytic philosophy of language, the Theory of Communication Language. This interdisciplinary approach has resulted in the development of methods for forming the code of knowledge and skills utilizing the language used by entrepreneurs. The condition for success in applying its methods will be the development of Network of Education and Commerce, which was initiated as a pilot program on a regional scale (Wielkopolska Region Network of Education and Commerce). Further the expansion will depend on existing social needs. So far, the researchers were able to achieve two im- 
portant objectives: cognitive, involving further clarification of some of the causes of the problems of communication in the process of exchange of knowledge and skills as well as utilitarian, involving the development of the method of the need for technical knowledge and skills in the workplace, which widely applied facilitates the creation of codes of communication and their flexible adaptation to the changing needs of businesses.

\section{References}

[1] Wallis S.E., Cybernetics and Systems Theory in Management: Tools, Views, and Advancements, Published in the United States of America by Information Science Reference, Hershey, pp. 6, New York 2010.

[2] Hamrol A., How political and economic circumstances can influence pursuits of excellence in quality management, TQM\&BE, 2, 619-640, 2011.

[3] Love P.E.D., Fong P.S.W., Irani Z., Management of Knowledge in Project Environments, Elsevier Butterworth-Heinemann, pp. 81-85, Oxford 2005.

[4] Botha A.P., Knowledge living and working with it, Juta\&Co., Cape Town, pp. 82-86, South Africa 2007.

[5] Kamakar A., Datta B.S., Principles and Practice of Management and Business Communication, Published by Dorling Kindersley, pp. 175-190, Noida India 2012.

[6] Daft R.L., Kendrick M., Vershinina N., Management, South-Western Cengage Learning EMEA, pp. 345-392, 2010.

[7] Ray R., Enterprise Resource Planning, Tata McGraw Hill Education Private Limited, New Delhi 2011.

[8] Brewer P.D., Brewer K.L., Knowledge Management, Human Resource Management, and Higher Education: A Theoretical Model, Taylor \& Francis Group 2010.

[9] Jakobson R., Poetics in the light of linguistics, translated K. Pomorska, Contemporary theory of literary research abroad, elaboration: $\mathrm{H}$. Markiewicz, t. 2, s. 23-69, Kraków 1976; [reprint in:] Looking for the essence of the language, red. M.R. Mayenowa, pp. 77-124, Warszawa 1989.

[10] Diering M., Dyczkowski K., Hamrol A., New Method for Assessment of Raters Agreement Based on Fuzzy Similarity Book Series: Advances in Intelligent Systems and Computing, 368, 415-425, 2015.

[11] Szafrański M., Managing Accelerated Enterprise Resources of Knowledge Creation, Wydawnictwo Politechniki Poznańskiej, pp. 235-246, Poznań 2015.
[12] Hamrol A., Kowalik D., Kujawińska A., Impact of chosen work condition factors on quality of manual assembly process, Human Factors and Ergonomics in Manufacturing, 21, 2, 156-163, 2011.

[13] Piwowarski R., Secondary education in Poland Guide to secondary education in Europe, Kallen D. [Ed.], Council of Europe Press, 1996.

[14] https://men.gov.pl/ministerstwo/informacje/zmianyw-ksztalceniu-zawodowym-dla-rynku-pracy.html\# prettyPhoto, access on: 24.01.2017.

[15] Boud D., Molly E., Higher and Professional Education - Understanding it and doing it well, USA, Canada Routlege 2013.

[16] Lawrence L., Wilkes, L., Ashmore, The reflective practitioner in professional education, Palgrave 2014.

[17] Rauner F., Maclean R., Handbook of Technical and Vocational Education and Training Research, Springer Science + Business Media B.V. 2008.

[18] Rumble G., Oliveira J., Vocational Education at a Distance - International Perspectives, Routledge, New York 2013.

[19] Szafrański M., Proposing Support for Preventive Actions in Enterprises by using Wielkopolska Region Educational and Vocational Counseling Tool, Employee in Management systems, T. Borys, P. Rogala [Eds.], Wydawnictwo Uniwersytetu Ekonomicznego we Wrocławiu, pp. 55-67, Wrocław 2013.

[20] Pilz M., Berger S., Canning R., Fit for Business, Pre - Vocational Education in European Schools, Springer VS, pp. 61-89, 2012.

[21] Ministry of National Education, Information for Employers - procedure for Introducing a New Occupation into the Classification of Professions of Vocational Education, https://men.gov.pl/ksztalceniezawodowe/wskazowki-praktyczne/informacja-dlapracodawcow-procedura-wprowadzania-nowegozawodu-do-klasyfikacji-zawodow-szkolnictwa-zawodowego.html, Warszawa 2016.

[22] Goźlińska E., Kruszewski A., Status of Vocational Education in Poland. Report, KOWEZiU, pp. 153155, Warszawa 2013.

[23] Borys E., The Bitterness of Success - male/female Teacher Between School Practice and Business Practice, Schools and Employers - Together for Better Vocational Education Quality, KOWEZIU, p. 92, Warszawa 2012.

[24] European Centre for the Development of Vocational Training, Briefing note: Permeable education and training systems: reducing barriers and increasing opportunity, 2012.

[25] Szafrański M., Traineeship - Knowledge Management Tool to Help Companies Reduce Costs, Organization Review No. 1, pp. 29-35, 2015. 
[26] Szafrański M., Acceleration of educating as an external factor supporting preventive and improving actions in businesses, Procedia Manufacturing; 6th International Conference on Applied Human Factors and Ergonomics and the Affiliated Conferences, AHFE 2015, T. Ahram, W. Karwowski, D. Schmorrow [Eds.], 3, 4948-4955, 2015.

[27] Prechtl P., Introduction to the Philosophy of Language, Wydawnictwo WAM, p. 199, Kraków, 2007.

[28] Russel B., Research on Meaning and Truth, Wydawnictwo WAM, Kraków, 2011.

[29] Rosch E., Family Resemblance: Studies in the Internal Structure of Categories, Cognitive Psychology, 7, 573-605, 1975.

[30] Varela F.J, Thompson E., Rosch E., The Embodied Mind - Cognitive Science and Human Experience, Massachusetts Institute of Technology, pp. 37-52, 1993.

[31] Kahnman D., Slovic P., Tversky A., Judgment under uncertainty: Heuristic and biases, Cambridge University Press, pp. 515-518, 1982.

[32] Ross B.H., The psychology of learning and motivation, Elsevier Inc., pp. 230-258, 2012.

[33] Mantura W., Outline of the Qualification, Wydawnictwo Politechniki Poznańskiej, Poznań 2010 .

[34] Putnam H., Is semantic possible, [in:] E. Margolis, S. Laurence [Eds.], Concepts, Care Readings, Cambridge, Mass.: MIT Press 1999.

[35] Pinker S., The Blank Slate - The modern denial of human nature, Penguin Books, 2016.

[36] Reed S.K., Cognition Theories and Applications, Wadsworth Cengage Learning, pp. 237-265, 2013.

[37] The Law Journal of the Republic of Poland, pos. 184, Regulation of the Minister of National Education, On the Core Curriculum of Vocational Education, 17.02.2012, Warszawa 2012.

[38] Wielkopolska Region Monitoring and Forecasting System for Vocational Training, Szafrański M. [Ed.], Wydawnictwo Politechniki Poznańskiej, Poznań 2011.

[39] Starzynska B., Grabowska M., Hamrol A., Effective Management of Practitioners' KnowledgeDevelopment of a System for Quality Tool Selection, 3rd International Conference on Social Science, DEStech Publication Inc., Lancaster, Pensylvania, USA, 2016.

[40] Practical Laboratories as a Tool to Accelerate the Diffusion of Technical Knowledge in Enterprises, [in:] Between the Management of Educational Processes and the Labor Market, Iwona Werner and Ewa Więcek-Janka [Eds.], Entrepreneurship and Management, Vol. XV, Book 8, Part III,
Wydawnictwo Społecznej Akademia Nauk, pp. 7589, Łódź 2014.

[41] Kubiak B., Korowiecki A. [Eds.], Human Computer Interaction, Fundacja Rozwoju EG, p. 102, Gdańsk 1997.

[42] Szafrański M., Wyrwicka M., Goliński M., A professional system as an example of an educational and economic network, "Теориа и практика стратеричного управлиния розвитком галузевих и региональих Суспильних систем", Ивано$\Phi$ ранкивський национальний техничний университет нафти и газу, Ивано-Франкивськ, рр. $62-$ $64,2015$.

[43] Szafrański M., Ganowicz M., Goliński M., Developing Corporate Social Responsibility in Educational and Economic Network, Social Responsibility and Sustainable Development in Management Science. Theoretical and applied aspects, J. Ejdys [Ed.], Wydawnictwo "Dom Organizacji", pp. 99114, Toruń 2016.

[44] Szafrański M. [Ed.], Wielkopolska Region Monitoring and Forecasting System for Vocational training, Wydawnictwo Politechniki Poznańskiej, Poznań 2011.

[45] Cabré M.T., Terminology: Theory, Methods and Applications pp. 14, 20, 38, Amsterdam 1999.

[46] Ogden C.K., Richards I.A., The Meaning of Meaning, p. 11, Londyn 1923.

[47] Lipka L., English Lexicology, Lexical structure, word semantics 83 word - formation, Gunter Narr Verlag Tübingen 2002, pp. 57.

[48] Communication in a Mechanized World The impact of Technical Progress on Language and Literature in Vocational Education, Walczak B., Niekrewicz A.A, Żurawska-Chaszczewska J. [Eds.], pp. 11-56, Gorzów Wielkopolski 2014.

[49] Rychter K.J., Chmielewski Z., Tworzydło D., Identity, Visual Sign, System, Image, pp. 17-24, Newsline 2012.

[50] Lakoff G., Johnson M., Metaphors We Live By, Chicago: Univeristy of Chicago Press, pp. 94-156, 1980.

[51] In cooperation with Grady J.E., From Perception to Meaning - Image Schemas in Cognitive Linguistics Hampe B. [Ed.], Mouton de Gruyter, pp. 35-45, Berlin 2005.

[52] Bense M., The World Through the Prism of the Sign, Państwowy Instytut Wydawniczy, p. 6, Warszawa 1980.

[53] Dylak S., Visual Literacy as the Competence of Modern Man, Dylak S., Skrzydlewski W., Media. Education. Culture. Towards media education, p. 119, Poznań-Rzeszów 2012. 